than at a temperature below this. Thus, from general practice, the inoculated plate can be sent to the laboratory for incubation and interpretation. If this is impossible the plates can be kept by the practitioner and only " positives" submitted for identification and sensitivity testing. Unfortunately organisms causing infections in other situations are much more fastidious in their growth requirements, and it is not possible, therefore, to use modifications of this method for other bacteriological investigations.

MacConkey plates were used because they support the growth of virtually all organisms responsible for acute urinary tract infections, and they inhibit the swarming of Proteus species. They can be obtained pre-poured from commercial sources and do not deteriorate during 7 to 10 days at room temperature, especially if kept in plastic bags.

Other commercial cotton-wool swabs could doubtless be used equally well, but would require initial calibration with more accurate methods. Serum-coated swabs, being water-repellent, are unsuitable.

Though $10^{5}$ organisms per $\mathrm{ml}$. of urine has come to be regarded by many as the figure below which urinary infection is not present this is not always so. As was pointed out in Kass's (1955) original paper one of the circumstances in which, with an active urinary infection, fewer organisms are found is when there is frequency of micturition. There is then insufficient incubation time in the bladder for organisms to reach $10^{5} / \mathrm{ml}$. of urine. In general practice there is often "built-in" frequency, as many patients micturate immediately before leaving home. Specimens of urine obtained in these circumstances may therefore have fewer than $10^{5}$ organisms per $\mathrm{ml}$. in the presence of infection. Diuresis also significantly reduces the number of organisms (Roberts et al., 1967). Other less well recognized factors, such as the excretion of inhibitory substances from the diet, may also account for fewer than $10^{5}$ organisms per $\mathrm{ml}$. in the presence of infection. These factors must be considered in reading screening tests, just as they are in the interpretation of routine cultures. It is not necessarily of any disadvantage, therefore, that accurate counts between 250 and 500 colonies per inoculum are not possible. Indeed, it is questionable whether the rigid application of accurate methods is justifiable on such variable material. This can sometimes be undoubtedly misleading.

\section{Summary}

A cultural method for the investigation of urinary tract infections using commercially available cotton-wool swabs to inoculate MacConkey plates with freshly voided urine is described. This is simple to use, and does not necessaril require incubation at $37^{\circ} \mathrm{C}$. Cultural methods have advantage: over chemical screening tests, but some described previously require special equipment and thus are an added burden of laboratory preparation facilities.

We wish to acknowledge the co-operation of Dr. Betty Bass ir the part of the investigation carried out in general practice and of Sister E. F. Williams, of the Gynaecological Outpatient Departmen1 at the Royal Free Hospital, and the technical assistance of Mrs J. Wood, B.Sc.

Disposable swabs were obtained from Grahams Medical Product: Ltd., St. Jude Works, Westmoor Street, London S.W.7. Pre-pourec MacConkey plates can be obtained from Oxoid Ltd., London S.E.1

\section{REFERENCES}

Bradley, J. M., and Little, P. J. (1963). Brit. med. F., 2, 361.

Brit. med. $7.1965,1,605$.

Cruickshank, R. (editor) (1965). Medical Microbiology, 11th ed., p. 870 London.

Guttmann, D., and Naylor, G. R. E. (1967). Brit. med. F., 3, 343.

Iind Stokes, E. J. (1963). Ibid., 1, 1384.

Hinton, N. A., and van der Hoeven, E. (1965). Canad. med. Ass. 7., 93 639.

Hoeprich, P. D. (1960). F. Lab. clin. Med., 56, 899.

Kass, E. H. (1955). Amer. F. Med., 18, 764.

Kincaid-Smith, P., Bullen, M., Mills, J., Fussel, U., and Huston, $N$ (1964). Lancet, 2, 61.

Leigh, D. A., and Williams, J. D. (1964). 7. clin. Path., 17, 498.

Mackey, J. P., and Sandys, G. H. (1965). Brit. med. J., 2, 1286.

Mond, N. C., Percival, A., Williams, J. D., and Brumfitt, W. (1965) Lancet, 1, 514.

O'Sullivan, D. J., FitzGerald, M. G., Meynell, M. J., and Malins, J. M (1960). f. clin. Path., 13, 527.

Roberts, A. P., Robinson, R. E., and Beard, R. W. (1967). Brit. med. 9 1,400 .

Simmons, N. A., and Williams, J. D. (1962). Lancet, 1, 1377.

Smith, L. G., Thayer, W. R., Malta, E. M., and Utz, J. P. (1961). Ann intern. Med., 54, 66.

\title{
Blood Loss Using the Modified Two-layer Kiil Dialyser
}

\author{
D. B. EVANS,* M.B., M.R.C.P. ; E. M. CLARKSON, $\dagger$ B.SC. ; J. R. CURTIS, $\ddagger$ M.B., M.R.C.P.
}

Brit. med.F., 1967, 4, 651-653

One of the factors contributing to the anaemia of patients undergoing intermittent haemodialysis is blood loss due to blood remaining in the dialyser and extracorporeal circuit at the end of dialysis.

The present study was undertaken to determine the volume of blood remaining in the dialyser and arterial and venous blood lines at the end of dialysis, and to compare the efficiency of various techniques used to rinse back the blood in the dialyser and blood lines into the patient via the venous cannula at the end of dialysis.

\section{Methods}

\section{Methods of Determining Volume of Blood Remaining in Dialyser and Blood Lines at End of Dialysis}

A sample of the patient's blood was taken into a Sequestrene tube at the end of dialysis. Suitably diluted, this served as a standard with which to compare the haemoglobin concentration in the wash solution obtained from the dialyser and blood lines.

When dialysis had been discontinued the blood lines and dialyser were washed through with tap-water until the washings were colourless. The dialyser was then dismantled and any blood remaining on the cuprophane membranes was washed off with tap-water. All washings were collected and the total volume was measured. After careful mixing, an aliquot from the washings was taken and stored at $-15^{\circ} \mathrm{C}$. or $+4^{\circ} \mathrm{C}$. with the post-dialysis blood sample from the patient until the haemoglobin concentrations were estimated. Then $0.2 \mathrm{ml}$. of wellmixed whole blood from each patient was diluted to $50 \mathrm{ml}$. with $0.05 \%$ ammonia. Any intact red cells remaining in the wash solution were lysed by the addition of a small amount of

\footnotetext{
* Senior Medical Registrar, Renal Unit, Addenbrooke's Hospital, Cam-

+ Biochemist, Charing Cross Hospital Medical School, Fulham Hospital London.

‡Lecturer in Medicine, Charing Cross Hospital Medical School, Fulham Hospital, London.
} 
saponin. The wash solution was centrifuged and then diluted in $0.05 \%$ ammonia solution to give approximately the same haemoglobin concentration as the whole blood standard.

The haemoglobin concentration in each diluted wash solution was compared with its own whole blood standard either as oxyhaemoglobin by reading direct in a colorimeter at $540 \mathrm{~m} \mu$ or as cyanmethaemoglobin. Conversion of the haemoglobin to cyanmethaemoglobin was found to be necessary only when bloods and wash solurions had been stored at $4^{\circ} \mathrm{C}$. for more than 24 hours. The mean difference in 20 estimations carried out by the two methods in parallel was $0.7 \%$ (S.D. 2.6).

The haemoglobin remaining in the dialyser and blood lines at the end of dialysis was expressed as millilitres of the patient's blood.

\section{Dialysis Techniques}

Permanent Teflon-Silastic arteriovenous shunts are used. A single pass system is employed with modified two-layer Kiil dialysers and cuprophane membrane (PT 150). Initially the dialysis fluid was not heated, and this necessitated long venous blood lines so that the patient's blood could be rewarmed before being returned from the dialyser to the venous cannula. The dialysis fluid is now heated to $37^{\circ} \mathrm{C}$. so that blood rewarming is no longer necessary and shorter venous lines can be used.

\section{Wash-back Techniques at End of Dialysis}

(1) During the period when blood rewarming was employed and long venous blood lines were used a comparison was made between two methods of washing back the blood at the end of dialysis. In one technique, at the end of dialysis the arterial blood line was clamped and cut near the patient's arterial cannula and then $500 \mathrm{ml}$. of $0.9 \%$ saline was infused into the arterial line. The dialyser in this technique was kept in the horizontal position throughout. The dialysis flow was continued at $500 \mathrm{ml} . /$ minute throughout. The other technique was similar except that the dialyser was tilted at an angle of $45^{\circ}$, with the arterial end raised during the last half-hour of dialysis. Each technique was carried out on 10 occasions in the same dialyser and on nine occasions in another dialyser. The volume of blood remaining in the dialyser and extracorporeal circuit was determined on each occasion.

(2) After the first study the technique of dialysis was changed and warm dialysis fluid was used so that rewarming of the blood was unnecessary. As a result of this it was possible to use shorter venous lines. After the introduction of these modifications two other wash-back techniques were compared. In one the dialyser was tilted at $45^{\circ}$, with the arterial end raised for the last half-hour of dialysis, and then at the end of dialysis $1,000 \mathrm{ml}$. of $0.9 \%$ saline was infused into the arterial line. In the other method the dialyser was tipped vertically with the arterial end uppermost during the last half-hour of dialysis and then at the end of dialysis $1,000 \mathrm{ml}$. of $0.9 \%$ saline was infused into the arterial line. With both of these techniques the dialysis flow was continued at $500 \mathrm{ml}$./minute throughout. Each technique was employed on nine occasions with the same dialyser, the volume of blood remaining in the dialyser and extracorporeal circuit being measured on each occasion.

\section{Use of Most Efficient Wash-back Technique in Different Kiil Dialysers}

The most efficient wash-back technique proved to be the one which included vertical tipping of the dialyser during the last half-hour of dialysis together with a rinse of $1,000 \mathrm{ml}$. of $0.9 \%$ saline at the end of dialysis. In the final part of the study this technique was used in nine different Kiil dialysers and the residual blood volumes were compared.

\section{Results}

(a) Use of Long Blood Lines (Blood Rewarmed) $+500 \mathrm{ml}$. $0.9 \%$ Saline and Dialyser Horizontal or Tilted $45^{\circ}$.-Table I shows volumes of blood remaining in the dialysers and blood lines with the two techniques. Twenty experiments were carried out with dialyser S II and 18 with dialyser S III. The volume of blood remaining when the dialysers were tilted during the last half-hour of dialysis tended to be smaller than when they were kept horizontal, but the difference between the means was not significant.

TABLE I

\begin{tabular}{c|c|c|c}
\multicolumn{2}{c}{$\begin{array}{c}\text { S II Dialyser } \\
\text { Volume of Blood (ml.) }\end{array}$} & \multicolumn{3}{c}{$\begin{array}{c}\text { S III Dialyser } \\
\text { Volume of Blood (ml.) }\end{array}$} \\
\hline $45^{\circ}$ & Horizontal & $45^{\circ}$ & Horizontal \\
\hline 75 & 60 & 71 & $54 \cdot 5$ \\
74 & 117.5 & 84 & 112.5 \\
43 & 140 & 78 & 97 \\
99 & 122 & 68 & 107 \\
83.5 & 278 & 90 & 1182 \\
106 & 99 & 102 & 120 \\
118 & 94 & 130 & 146 \\
105 & 108 & 106 & 119 \\
67 & 149 & 89 & 113 \\
120 & 263 & & 25 \\
\hline Mean & 89 & 91 & $54.5-146$ \\
S.D. & 143 & 18 & \\
Range $43-120$ & $60-278$ & $68-130$ & \\
\hline
\end{tabular}

(b) Using Short Blood Lines (Warm Dialysis Fluid) $+1,000$ ml. $0.9 \%$ Saline and Dialyser Tilted to $45^{\circ}$ or Vertically.Table II shows results of 18 experiments in one dialyser. The mean volume with the dialyser at $45^{\circ}$ was $52.9 \mathrm{ml}$., while with the dialyser vertical it was $16.9 \mathrm{ml}$. The difference between the means was highly significant $(t=8.3 ; \mathrm{P}<0.001)$.

TABLE II.-H III Dialyser. Volume of Blood (ml.)

\begin{tabular}{ll|l|l|l|l|l|l|l|l|l}
\hline $\begin{array}{l}45^{\circ} \\
\text { Verticai }\end{array}$ & $\cdots$ & 28.6 & 68.6 & 68.4 & 35.5 & 51.2 & 51.2 & 64.2 & 53.4 & $55.4 *$ \\
& $\cdots$ & 13.0 & 10.0 & 30.9 & 32.7 & 14.8 & 15.8 & 10.3 & $6.7 \dagger$ \\
\hline
\end{tabular}

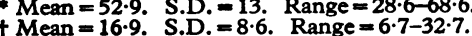

(c) Use of Most Efficient Wash-back Technique in Different Kiil Dialysers.-Vertical tipping of the dialyser during the last half-hour of dialysis together with a rinse of $1,000 \mathrm{ml}$. of $0.9 \%$ saline at the end of dialysis proved to be the most efficient of the wash-back techniques used in this study. The results of residual blood volumes found in nine different Kiil dialysers after using this technique are shown in Table III.

\begin{tabular}{|c|c|c|c|c|c|c|c|c|c|}
\hline \multicolumn{10}{|c|}{ TABLE III } \\
\hline $\begin{array}{l}\text { Dialyser } \\
\text { Volume of } \\
\text { blood (ml.) }\end{array}$ & $\begin{array}{c}\mathrm{A} 2 \\
31 \cdot 3\end{array}$ & $\begin{array}{c}\text { A3 } \\
16.9\end{array}$ & $\begin{array}{c}\text { A5 } \\
29 \cdot 2\end{array}$ & $\begin{array}{l}\text { B2 } \\
21\end{array}$ & $\begin{array}{l}\text { B6 } \\
4\end{array}$ & $\begin{array}{l}\mathrm{Cl} \\
4\end{array}$ & $\begin{array}{l}\text { C2 } \\
0.9\end{array}$ & $\begin{array}{l}\text { C5 } \\
6 \cdot 4\end{array}$ & $\begin{array}{l}\mathrm{C} 8 \\
0.4\end{array}$ \\
\hline
\end{tabular}

\section{Discussion}

Priming with blood is unnecessary with the Kiil dialyser, but relatively large volumes of blood may be left in the dialyser and extracorporeal circuit at the end of dialysis. This loss of blood with each dialysis contributes to the anaemia of patients on intermittent haemodialysis.

Various techniques have been described to wash the blood remaining in the dialyser back into the patient via the venous cannula at the end of dialysis.

Cole et al. (1962), using Kiil dialysers, stated that if the dialyser was kept in the horizontal position at the end of dialysis and an attempt made to rinse the blood back with saline most of the red cells remained behind while mainly plasma was washed back into the patient. It was estimated that probably more than $100 \mathrm{ml}$. of packed cells was left behind in the dialyser at the end of each dialysis. If, however, the 
dialyser was tipped vertically, with the blood flowing downwards during the last 10 minutes of dialysis, and was then rinsed with saline, Cole et al. (1962) estimated that the loss of red cells was reduced by a half to one-quarter. This change in the wash-back technique resulted in a reduction in average transfusion requirements from 5 units/month to 2.5 units/ month.

Cole et al. (1963), again using Kiil dialysers, made some measurements of the volume of blood remaining in the dialyser and extracorporeal circuit by means of two wash-back techniques. In the first the dialyser was kept in the horizontal position throughout and $400 \mathrm{ml}$. of saline was used to rinse back the blood. With this technique the mean volume of blood remaining was $140 \mathrm{ml}$. (32 determinations). The second washback technique used was rather complicated and involved elevation of the arterial end of the dialyser by $15 \mathrm{in} .(38 \mathrm{~cm}$.) during the last half-hour of dialysis. In addition the dialysate flow was changed from countercurrent to concurrent by switching the dialysate tubes to opposite ends of the dialyser and increasing the dialysate flow from $500 \mathrm{ml}$./minute to 3-4 litres/ minute. The dialyser was then rinsed with saline, $100-\mathrm{ml}$. aliquots being run in via the arterial blood line with the dialysate flow temporarily stopped. The dialysate flow was then increased again to 3-4 litres/minute until blood flow ceased. This process was repeated until a total of $400 \mathrm{ml}$. of saline had been used to rinse the dialyser. With this technique the mean volume of blood remaining in the dialyser was very significantly reduced to $35 \mathrm{ml}$. (92 determinations).

Johnson et al. (1966), also using Kiil dialysers, rinsed the dialyser at the end of dialysis with $150-250 \mathrm{ml}$. of saline and found an average of $20 \mathrm{ml}$. of blood left behind. These workers do not state whether the dialyser was tilted in any way towards the end of dialysis.

In the present study we have confirmed that large volumes of blood may remain in the Kiil dialyser at the end of dialysis. Various wash-back techniques are compared, the most satisfactory of which involves tipping the dialyser vertically, with the blood flowing downwards, during the last half-hour of dialysis and rinsing with 1 litre of saline at the end of dialysis.
The mean volume of blood remaining when this technique was employed in nine experiments with the same dialyser was $16.9 \mathrm{ml}$. This method was then used in nine different dialysers, the mean volume of blood in the nine dialysers being $12.6 \mathrm{ml}$. Another factor contributing to these results is the improvement in the quality of the dialysers now produced by various manufacturers. It is notable that in five dialysers, four of which were produced in the last year, blood losses with the above washback technique were extremely small, with a mean of $3.1 \mathrm{ml}$. (range 0.4-6.4 ml.). It is also essential to be able to tip the Kiil dialyser vertically towards the end of dialysis, and trolleys designed to hold these dialysers must incorporate this facility.

\section{Summary}

Large volumes of blood may remain in the Kiil dialyser and extracorporeal circuit at the end of dialysis if inefficient washback techniques are employed and will contribute to the anaemia of patients on intermittent haemodialysis.

Several wash-back techniques were tried, and in three of these the mean volume of blood remaining in the Kiil dialyser and extracorporeal circuit varied from 52.9 to $143 \mathrm{ml}$.

The most efficient method used involves tipping the dialyser vertically so that the blood flows from the top downwards during the last half-hour of dialysis and rinsing with 1 litre of $0.9 \%$ saline at the end of dialysis.

This method was used with nine different Kiil dialysers. The mean volume of blood remaining in the dialyser and extracorporeal circuit was $12.6 \mathrm{ml}$.

We are indebted to Sister J. M. Storey and the staff of the Haemodialysis Unit, Fulham Hospital, for assistance in carrying out this study.

REFERENCES

Cole, J. J., Pollard, T. L., and Murray, J. S. (1963). Trans. Amer. Soc. artif. intern. Organs, 9, 67.

(1962). Ibid., 8, 209.

ohnson, W. J., Wagoner, R. D., Hunt, J. C., Mueller, G. J., and Hallenback, G. A. (1966). Mayo Clin. Proc., 41, 73.

\title{
Traveller's Diarrhoea : a Survey of Symptoms, Occurrence, and Possible Prophylaxis
}

\author{
ANTHONY C. TURNER,* M.R.C.S., L.R.C.P., D.OBST.R.C.o.G.
}

\author{
Brit. med. F., 1967, 4, 653-654
}

Traveller's diarrhoea, described by Gordon (1965) as a notorious world-wide illness lasting one to three days, presents a precipitous onset of loose stools and variable symptoms, including nausea, vomiting, abdominal cramps, etc. It of ten occurs sporadically as isolated cases, though epidemics occur within families or groups of travellers of all ages. The incidence varies according to geographical locations (Kean and Waters, 1958).

Previous studies (bacteriological and prophylactic) have been undertaken (Lie Kian Joe, 1956 ; Kean and Waters, 1959 ; Varela et al., 1959 ; Kean et al., 1962 ; Nelson et al., 1962) without producing definite conclusions regarding the value of prophylactics or the causal relation between diarrhoea and considered pathogens.

Dr. D. J. Cussen attended the U.K. Olympic teams in Rome 1960 and gave one tablet of Streptotriad twice daily; other

\footnotetext{
- Senior Overseas Staff Medical Ufficer, Air Corporations Joint Medical Service, London Airport, Hounslow, Middlesex.
}

teams had an appreciable amount of diarrhoea, but no cases occurred in the U.K. teams. As neomycin is widely used in gut infections, it was decided to undertake an extensive controlled prophylactic trial comparing Streptotriad, a neomycinsulphonamides compound, and a placebo in B.O.A.C. personnel and their families going abroad.

\section{Method}

Tablets $\mathrm{A}, \mathrm{B}$, and $\mathrm{C}$ were randomly allocated to 1,383 subjects (see Table), except that complete families were given the same tablet to avoid interchange of medication. Anyone with known drug allergy was excluded. Participants were told to maintain their usual standards of food hygiene and received instructions regarding dosage and duration of medication as follows: one tablet twice daily for the first two weeks while away, one tablet daily for the third week, then stop. Children under 12 years were given half this dosage. Two sealed letters indicating the 